\title{
A Study on Road Safety for the Visually Challenged - Policy Implications
}

\author{
Asha Bhatia ${ }^{1} \&$ Sanjwani Jayant Kumar ${ }^{2}$ \\ ${ }^{1}$ Department of General Management, K. J. Somaiya Institute of Management Studies \& Research, Mumbai, \\ India \\ ${ }^{2}$ Operations Department, K. J. Somaiya Institute of Management Studies \& Research, Mumbai, India \\ Correspondence: Asha Bhatia. E-mail: ashabhatia@somaiya.edu, sanjiwani@somaiya.edu
}

Received: October 23, 2018

Accepted: December 13, 2018

Online Published: January 30, 2019

doi:10.5539/ass.v15n2p151

URL: https://doi.org/10.5539/ass.v15n2p151

\begin{abstract}
There is an increase in number of accidents, injuries and deaths due to a rise in motor vehicle population. India is a signatory of the Brasilia Declaration with an agenda to reduce the number of accidents by $50 \%$ by the year 2020 , yet it can be observed that the incidents of accidents have not decreased. There were 285 million visually impaired people in the world, of which 246 million had low vision and 39 million were blind as per the World Health Organization report (2012). It is alarming to note that around $90 \%$ of the blind live in the developing world. They are constantly dealing with challenges in their day to day life. Commuting by roads is all the more unsafe for these visually challenged pedestrians. This unique study has conducted an in depth interview to understand the needs and problems faced by the visually challenged pedestrians, followed by a primary survey on World White Cane Day to judge the extent of awareness of the correct technique. The appropriate techniques were then demonstrated to the general public, thus creating awareness and the behavioral changes needed in this endeavor. The paper has used a theoretical concept and practically suggests policy implication for empowering the disabled through awareness drives and collaborating with various government agencies.
\end{abstract}

Keywords: road safety, visually challenged, world white cane day, pedestrian awareness, behavioral changes, policy implications

\section{Introduction}

In metropolitan city like Mumbai, having population over 10,000,000, ranked 5th city globally accounting for maximum number of road crashes, common man finds it difficult to commute on busy roads. It is easily comprehendible how hard it must be for the visually impaired to commute.

With every road accident, life comes to halt not only for the victim, but also for the family. India is signatory of Brasilia Declaration which abides India to reduce road traffic rates by half by year 2020. In spite of this there is not much of difference in the given scenario, rate of road traffic deaths has been on the rise year on year.

Increasing road safety for visually impaired is an extremely important action called for, because unsafe roads hinder their growth and empowerment. If roads would be safer, they will be able to commute easily and lead a hassle free life.

To combat this issue a three phased research was conducted on World White Cane Day, celebrated on October 15 every year since 1964 to promote equal opportunities for visually impaired and World Day of Remembrance marked on 3rd Sunday of November every year in memory of millions who were killed and injured in road accidents and. These days were selected for the simple reason that they would create a greater impact among general public.

Another integral part of this research was creating awareness among people to come up and help the victim of road accident. Mostly people are hesitant to do so because of legal complexities that may arise in future. The Good Samaritan Law, which offers legal protection to people who assist someone injured or ill, was recently launched in India. People were informed about the recent development and the legal aid they receive on volunteering to help the victim.

\section{Literature Review and Theory Building}

With increase in number of vehicles on road, road accidents and subsequent deaths have also increased 
proportionally. In 2010, 5 Lakh accidents have been recorded in India. Victims of these accidents are mostly in age group of 25 to 65 and are bread earners of the family. Not only families end up losing their near and dear one but also an earning member, changing their lives drastically. World's middle income and low income countries account for ninety one percent of deaths due to road accidents, though they have less than half of world's automobiles. 1.9 million People may die annually by 2020 if a suitable action is not taken (World Health Organisation).

Countries which have been able to successfully curb number of road accidents have used techniques such as proper planning of design and infrastructure of roads, traffic management, etc. United Nations' Decade of Action for Road Safety 2011- 2020 has set a goal to save five million lives in this time period. (United Nations Road Safety Collaboration)

Ikram et al. (Ikram \& Mahajan, 2016) in the paper "Road accidents: Overview of its causes, avoidance scheme and a new proposed technique for avoidance", have discussed about road accidents, reasons of occurrence and measures to prevent them.

The authors Goniewicz et al. (Goniewicz, Goniewicz, Pawłowski, \& Fiedor, 2016) in the paper "Road accident rates: strategies and programs for improving road traffic safety" have analyzed that one of the most important health and social policy issues the governments across the globe face, is the problem of safety to avoid road accidents.

Haight (Haight, 1980) in the study on "Traffic safety in developing countries" mentions that safety parameters in countries falling in this category are dependent on natural trends and should consider low cost - effective solutions to address local problems.

In the developed countries like Japan, Canada, USA, etc, to ease the life of visually challenged, a tile has been invented using the concept of molecular tactile surfaces which are used on roads, walkaways and other areas. The USP of these tiles is that they have circular and elongated tactile projections, which can provide directions to blind pedestrians while walking. They are widely being used as a solution for pedestrian crossing by (Schmanski, 1987).

In the study by Altinsoy (Altinsoy, 2013) "The detectability of conventional, hybrid and electric vehicle sounds by sighted, visually impaired and blind pedestrians'" the authors realized that for road safety, it is important for pedestrians to timely detect the vehicles plying on the road. This study was conducted on 37 visually impaired participants. It aimed at investigating traffic condition in which a vehicle was approaching a pedestrian from a distance of 50 meters with partial acceleration. Sound of different vehicles was recorded such as 14 internal combustion engine, 4 hybrid cars and 6 electric cars.

The result from the experiment inferred that sound of electric vehicles was detected much later as compared to combustible engine. This implied that electric cars are hard to be detected by sound, and thus can lead to more causality.

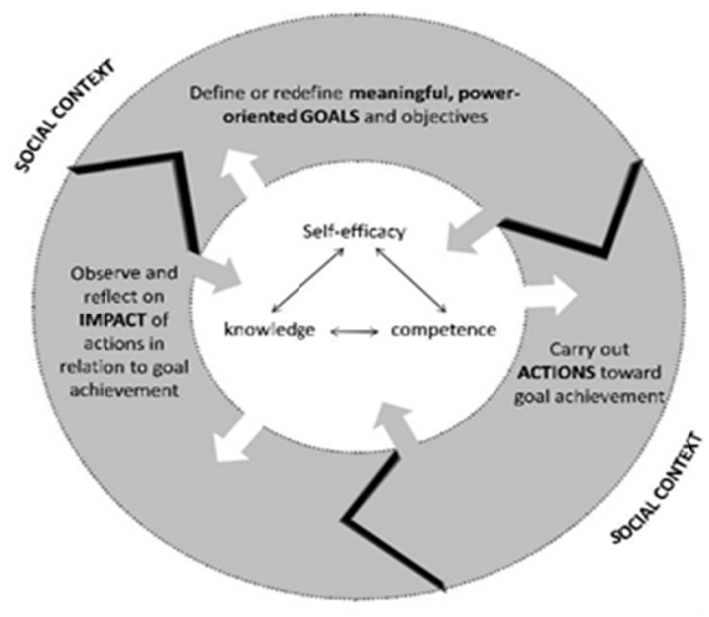

Figure 1. Source: Model by Lauren \& Aliya(2014)

Coming up with solutions to make process of commuting easier for visually impaired will actually lead to their empowerment and will open up doors of opportunities for them. 
Lauren and Aliya (Cattaneo \& Chapman, 2010) in their paper "The Process of Empowerment a Model for Use in Research and Practice" have described the Empowerment Process Model, which can be used as a base to understand how increasing road safety will help in empowerment of visually impaired.

Central concept of empowerment is improving human life, by gaining more power and acceptance at social and organizational level.

In this study, the authors have described Empowerment Process Model as amalgamation of six components. This was taken as a theoretical model and replicated for the study in the following manner:

i) Setting Personally Meaningful, Power Oriented Goal: The model suggests that process of empowerment is centrally driven by thrust to accomplish personal, meaningful and power oriented goals set by an individual or a group. The goal of survey conducted on World Remembrance Day and World White Cane Day was to create awareness among public about current situation of road safety for visually impaired in metropolitan cities.

ii) Self-Efficacy: Empowerment is directly dependent on individual's belief or the confidence they possess about their ability. Considering the survey, it helped visually challenged in increasing self- efficacy as they will be able to take up more opportunities.

iii) Knowledge: Once a person has goals set and has self-efficacy to pursue, next step is knowledge about plan of action required to fulfil them. Action plan undertaken under the initiative was targeting general public on important days such as World Remembrance Day and World White Cannes Day, so as to create greater impact.

iv) Competency: One needs to analyze the strengths, weakness, obstacles and opportunities prior to executing the action plan designed. Where the unplanned and unchanneled traffic of Mumbai is an obstacle, the strengths are new rules such as The Good Samaritan Law which encourages people to help victims of road accidents. Conducting survey on days which are directly related to issue was an opportunity.

v) Action: The research was broadly divided in three phases and was conducted on public of Mumbai city, which is bustling with traffic at all points of time. People were made aware of traffic issues faced by visually impaired, and how situations can be simplified for them so that they can commute with ease and empower themselves by travelling independently.

vi) Impact: Through the research various stakeholders who can create a difference in scenario of road safety were brought together on same platform. Also, through this common man came to know about the initiative and found a platform from where they can extend a helping hand in bringing a change.

Empowerment Process Model taken as a theoretical construct, explains in an elaborative way how the initiative and research taken will help in empowering visually impaired. Many of them are not able to earn a living or lead a normal life because they cannot travel independently on unsafe streets. But if awareness is created, and infrastructure is developed as per their requirements, they can be empowered to lead a normal life as any other person does and explore number of opportunities for their growth.

\section{Research Design and Methodology}

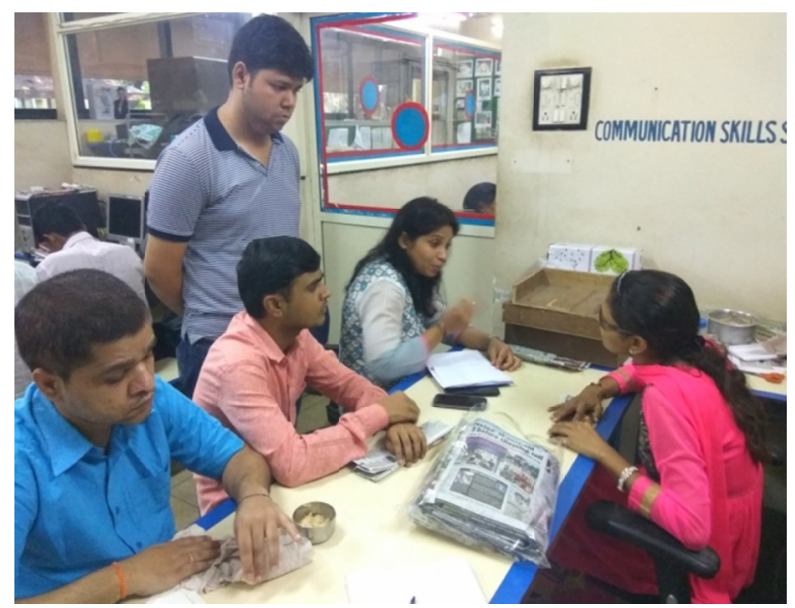

Figure 2. In depth interview of visually challenged at Department of Rehabilitation, National Association of Blind, Mumbai, India

A secondary research was conducted and data compiled to understand the statistical scenario of road accidents in the last few years. Many websites and research papers were referred to collate information about number of 
accidents, causes of accidents etc. Data from secondary sources was gathered to have an overview of the visually challenged population in India and the provisions made by the government to empower them.

Simultaneously a primary survey was carried out to get a clear understanding of what are the problems faced by this niche group and how can these be addressed.

On 15th Oct, 2016 which is World White Cane Day a field survey was conducted to understand the awareness amongst the general public about the right technique to help a blind person cross a street so as to avoid road accidents. World white cane day is celebrated worldwide to commemorate the achievements of the visually challenged and also to highlight the importance of the white cane, which stands as the symbol of the safety of the visually challenged people.

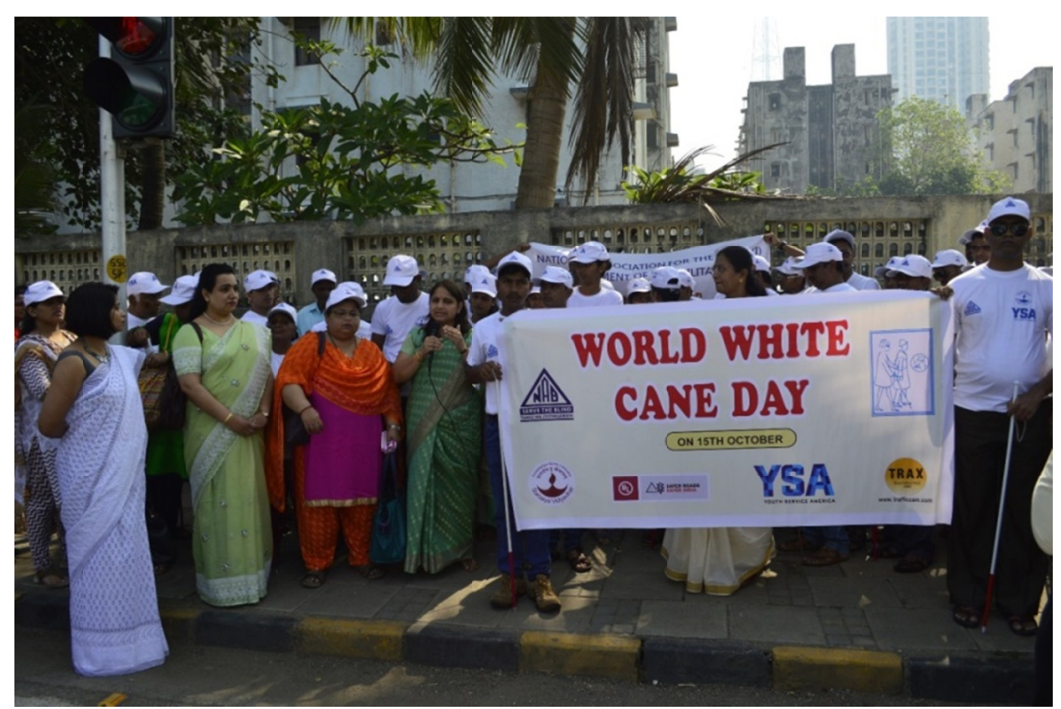

Figure 3. Celebration of World white cane day on $15^{\text {th }}$ October

\subsection{Objectives of Study}

1. To know whether commuters take note of visually challenged passengers.

2. To understand the awareness of guiding techniques to help visually challenged commuters.

3. To understand the awareness about any organization that works for the welfare of the visually challenged.

4. To know the willingness of people to associate with National Association for Blind (India).

\subsection{Basic Timeline}

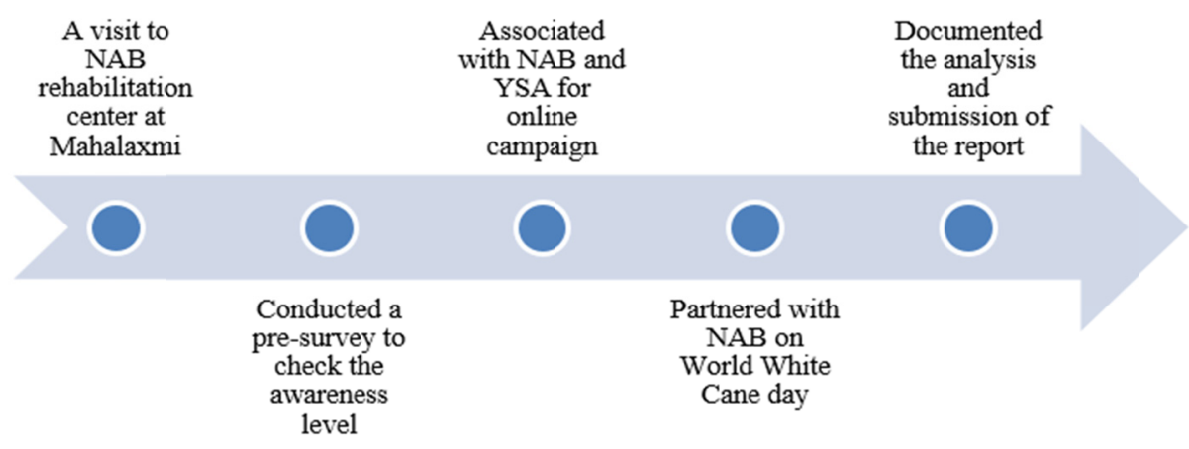

Figure 4. Planned timeline for the research 


\subsection{Data Analysis}

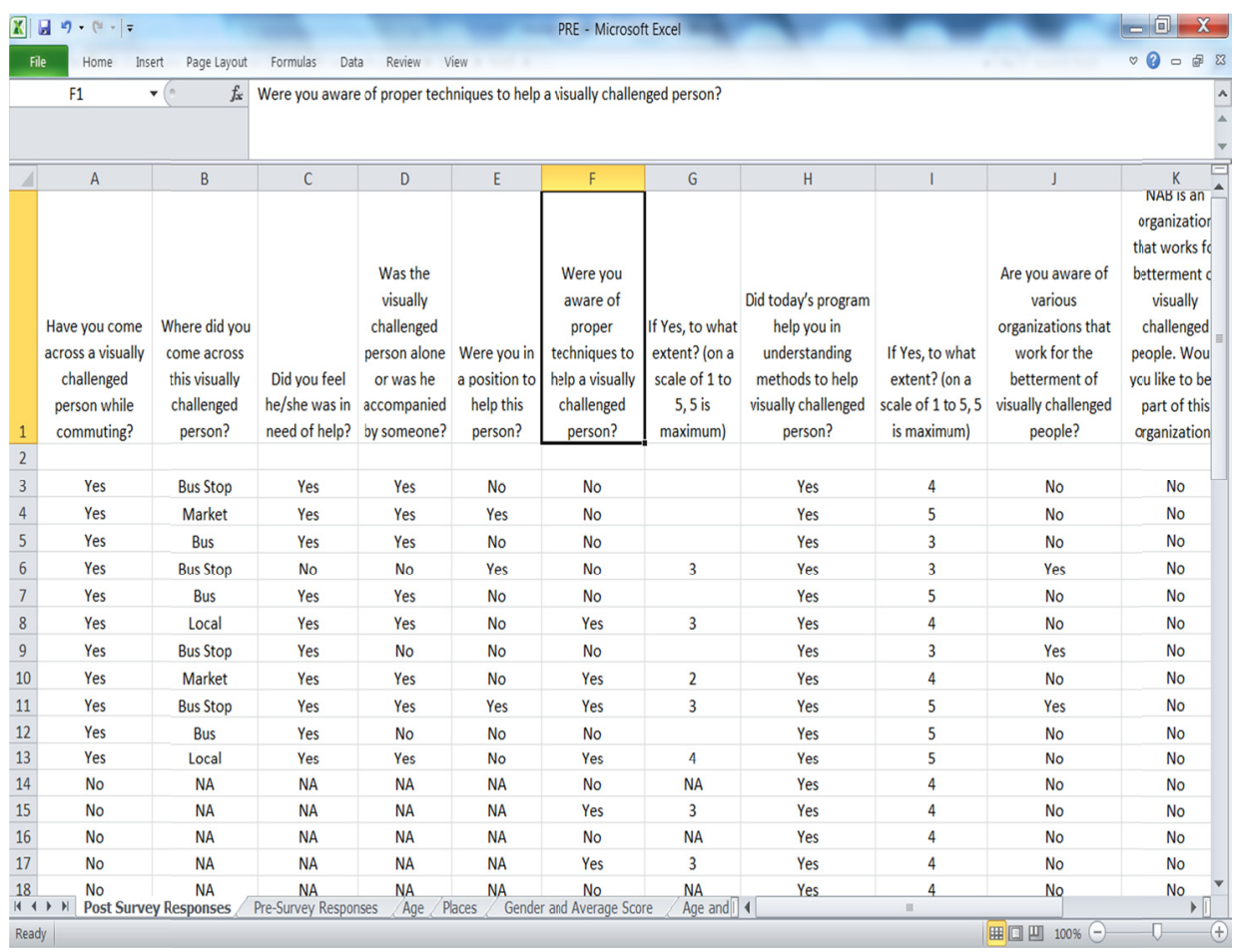

Figure 5. Data snapshot

\subsection{Descriptive Analysis}

In the primary data collected from pedestrians on World white cane day following inputs were obtained:

\begin{tabular}{|c|c|c|}
\hline Sr No. & Parameter & Analysis \\
\hline 1 & $\begin{array}{l}\text { Have you come across a visually challenged } \\
\text { person while commuting? }\end{array}$ & $\begin{array}{l}81 \% \text { of the respondents came across visually challenged } \\
\text { people while commuting on a daily basis. }\end{array}$ \\
\hline 2 & $\begin{array}{l}\text { Where did you come across this visually } \\
\text { challenged person? }\end{array}$ & $\begin{array}{l}\text { Places where visually challenged people are found by } \\
\text { respondents are majorly Bus stops, Trains, Rail way stations } \\
\text { and while crossing roads. }\end{array}$ \\
\hline 3 & Did you feel he/she was in need of help? & $\begin{array}{l}91 \% \text { of the respondents felt that visually challenged people } \\
\text { are in need of help }\end{array}$ \\
\hline 4 & $\begin{array}{l}\text { Was the visually challenged person alone or was } \\
\text { he accompanied by someone? }\end{array}$ & $39 \%$ of the visually challenged people were travelling alone. \\
\hline 5 & Were you in a position to help this person? & $\begin{array}{l}66 \% \text { of the commuters were in a position to help visually } \\
\text { challenged. }\end{array}$ \\
\hline 6 & $\begin{array}{l}\text { Were you aware of proper techniques to help a } \\
\text { visually challenged person? }\end{array}$ & $\begin{array}{l}\text { Approximately } 50 \% \text { of the respondents were aware of the } \\
\text { proper techniques to help Visually challenged. }\end{array}$ \\
\hline 7 & $\begin{array}{l}\text { If Yes, to what extent? (on a scale of } 1 \text { to } 5,5 \text { is } \\
\text { maximum) }\end{array}$ & $\begin{array}{l}\text { Only } 20 \% \text { of the respondents have confidence about the right } \\
\text { technique to help Visually challenged }\end{array}$ \\
\hline 8 & $\begin{array}{l}\text { Did today's program help you in understanding } \\
\text { methods to help visually challenged person? }\end{array}$ & $\begin{array}{l}96 \% \text { of the respondents properly understood the techniques } \\
\text { to help Visually challenged to cross road. }\end{array}$ \\
\hline 9 & $\begin{array}{l}\text { If Yes, to what extent? (on a scale of } 1 \text { to } 5,5 \text { is } \\
\text { maximum) }\end{array}$ & $\begin{array}{l}96 \% \text { have properly understood the technique which was } \\
\text { demonstrated to them on the WWCD. }\end{array}$ \\
\hline 10 & $\begin{array}{l}\text { Are you aware of various organizations that work } \\
\text { for the betterment of visually challenged people? }\end{array}$ & $\begin{array}{l}67 \% \text { of the respondents are not aware of the Organizations } \\
\text { working for Visually challenged. }\end{array}$ \\
\hline 11 & $\begin{array}{l}\text { NAB is an organization that works for betterment } \\
\text { of visually challenged people. Would you like to } \\
\text { be a part of this organization? }\end{array}$ & $\begin{array}{l}\text { Approximately } 50 \% \text { of the respondents agreed to participate } \\
\text { in NAB activities. }\end{array}$ \\
\hline 12 & Gender & 99 males and 51 females participated in the WWCD program \\
\hline 13 & Age & Average age of the respondent is 37 years \\
\hline
\end{tabular}




\section{Bridging the Gap}

A primary survey was carried out to understand the problems faced by the visually challenged community who have to commute for their personal and professional commitments. The authors did their bit to create awareness with partnering organizations like Mumbai Traffic Police, Bombay Municipal Corporation National Association for the Blind (India) and made an effort to bridge the gap between these organizations and the general public.

\subsection{World White Cane Day}

An event was conducted in Mumbai, India, on 15th October, World White Cane Day. This was an awareness drive to highlight the challenges faced by the visually challenged people and on making Mumbai roads safer for them. The awareness campaign was carried out in partnership with National Association for the Blind(India) \& Mumbai Traffic Police under the aegis of UL Safer Roads Safe India \& Youth Services America Busy traffic junctions across Mumbai were identified to execute the event. The celebration of World White Cane day started from the office of NAB (India), Mumbai. Student volunteers of a management institute gave demonstrations regarding the correct techniques of how to help a visually challenged person cross a street safely. Banners and pamphlets were also used judiciously to disseminate information to the general public. The vigilant volunteers carried out a survey and documented the responses of the commuters before and after the demonstration which led to interesting insights and a heightened level of volunteerism. "People not only extended their support to help the visually challenged, but also shared their consent to get associated with NAB (India)", stated a member of the management institute.

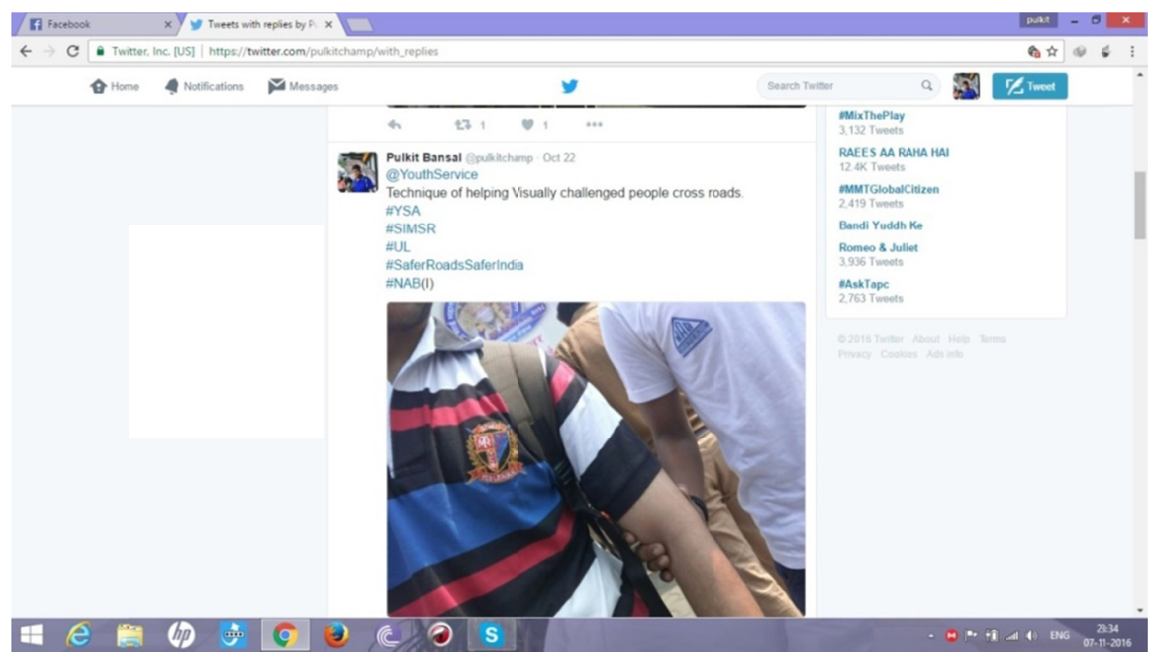

Figure 6. Twitter handle for the demonstration of using the correct helping technique for helping the visually challenged

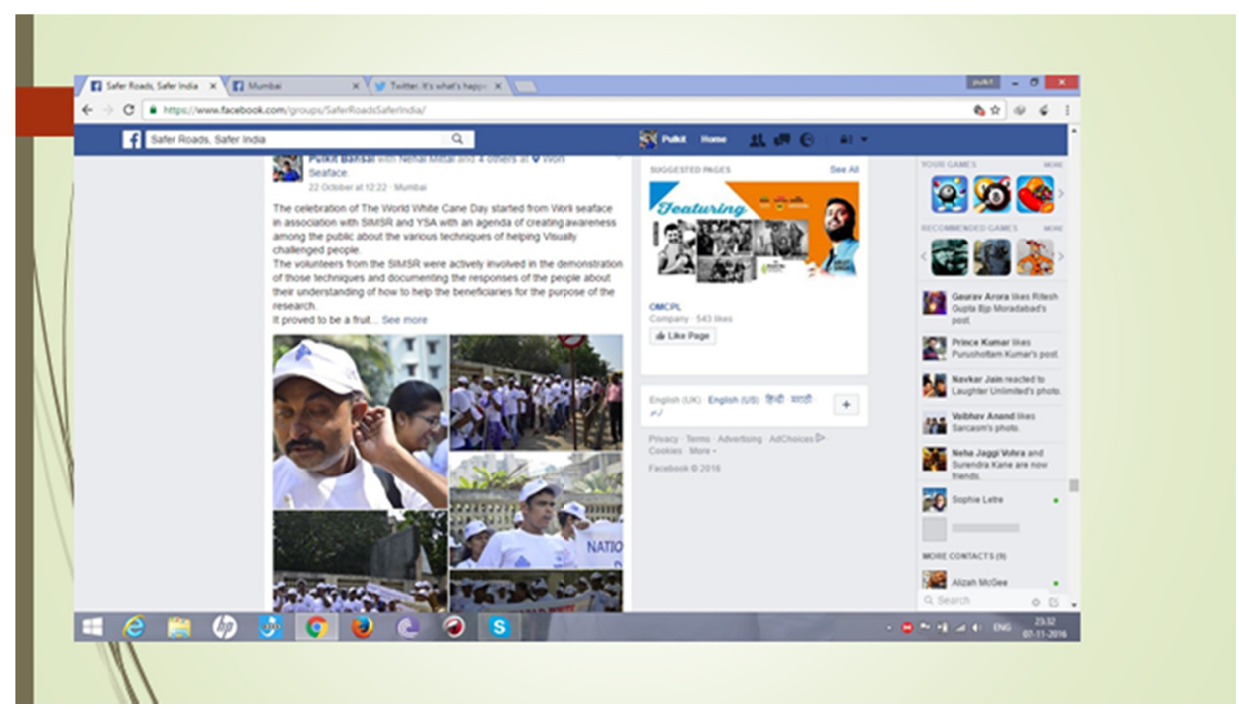

Figure 7. Facebook page for the activities carried out on occasion of World white cane day on $15^{\text {th }}$ October 


\subsection{Event to Commemorate the World Remembrance Day}

The World Day of Remembrance for Road Traffic Victims is commemorated on the third Sunday of November every year to remember the millions killed and injured on roads together with their families, friends and many others who are also affected. The event conducted on 20th November 2016, was the commemoration of the World Day of Remembrance for Road Traffic Victims.

As a part of observing the World Remembrance Day for Road and Traffic Victims, an awareness campaign regarding the legalities involved post accidents was actively carried out through social media for a week. Facebook and Twitter were flooded with interactive knowledge sharing posts and discussions about the various laws for the protection of those who help the road accidents' victims. Along with this, a workshop on self-defense techniques for road safety was conducted for the students in the campus. The event turned out to be a huge success with the message of importance of road safety being rightfully delivered across.

\subsection{Good Samaritan Law}

Street plays were organized across the campus to create awareness regarding the recently implemented Good Samaritan Law in India.

It has been observed that by standers do not come forward to help in case of an accident fearing legal implications and repercussions. A Good Samaritan is one who voluntarily comes forward to provide assistance in case of an emergency, accident or a crash. One can call for help, provide first aid and rush the victim to the nearest hospital but in return expects no reward or appreciation. On March 30, 2016, the Supreme Court of India gave "force of law" to the guidelines for the protection of Good Samaritans issued by the Ministry of Road Transport and Highways (https://savelifefoundation.org/gsl-microsite/accessed on May 2018). The purpose of a Good Samaritan law is to provide legal protection to any person who comes to the aid of victims of road accidents. They cannot be forced to reveal their personal details and are protected by law. The participants of the street play also urged the spectators to take a pledge to be a Good Samaritan.

Hence the events carried out by the volunteers over a period of time reinstated the message of road safety amongst the general public and encouraged them to help their visually challenged brethren.

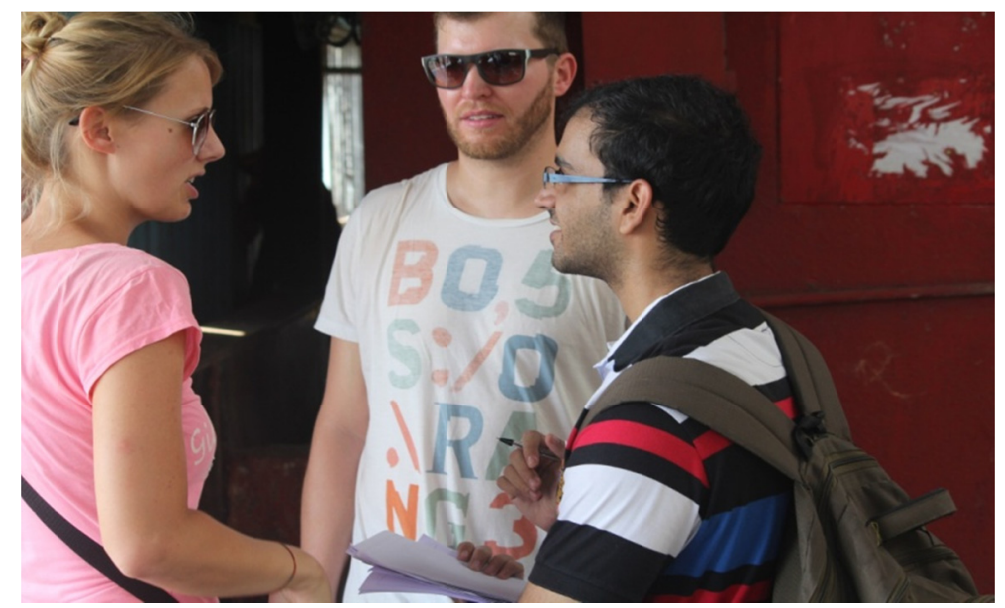

Figure 8. Understanding the perception of global citizens towards those who are visually challenged

\section{Section 5}

\subsection{Conclusions and Recommendations}

There is a need to understand the problems faced by commuters and the visually challenged in particular. The general public is willing to help but has no idea of what they need to do. The correct techniques of helping a blind person need to be publicized. Post-accident facilities such as First-Aid, Ambulance services need to be made readily available. The local police, government and citizens should work in collaboration towards reducing the frequency of accidents.

\subsection{Policy Implications}

This study has thrown up certain policy implications which will help the visually challenged commuters. For the totally blind persons, provisions can be made of a beeper to be installed at certain traffic junctions. Where there are institutions for the blind in the vicinity, the signal can be delayed at the red light so as to allow them the ease of crossing the road. 
Infrastructural changes such as a different texture of the road at the zebra crossing can be used so as to clearly demarcate the area. Tactile tiles structure should be included (Schmanski, 1987).

For the partially sighted persons, broader strips at zebra crossings, color contrasts can be incorporated. Awareness can be created through social media platforms and also by collaborating with other government agencies and through public private partnerships. Thus the study will be useful for better governance.

\section{Acknowledgement:}

Youth Services of America for the financial grant and Post Graduate students from the K. J Somaiya Institiue of Management Studies \& Research, Mumbai for their contribution to the project are duly acknowledged.

\section{References}

Altinsoy, E. (2013). The detectability of conventional, hybrid and electric vehicle sounds by sighted, visually impaired and blind pedestrians. In INTER-NOISE and NOISE-CON Congress and Conference Proceedings, 247(3), 4358-4362, Institute of Noise Control Engineering.

Cattaneo, L. B., \& Chapman, A. (2010). The Process of Empowerment A Model for Use in Research and Practice. George Mason University. https://doi.org/10.1037/a0018854

Goniewicz, K., Goniewicz, M., Pawłowski, W., \& Fiedor, P. (2016). Road accident rates: strategies and programmes for improving road traffic safety. European journal of trauma and emergency surgery, 42(4), 433-438. https://doi.org/10.1007/s00068-015-0544-6

Haight, F. A. (1980). Traffic safety in developing countries. Journal of safety research, 12(2), 50-58.

https://savelifefoundation.org/gsl-microsite/accessed on May 2018

Ikram, N., \& Mahajan, S. (2016). Road accidents: Overview of its causes, avoidance scheme and a new proposed technique for avoidance, In Computing for Sustainable Global Development (INDIACom). In $3 \mathrm{rd}$ International Conference IEEE (pp. 497-499).

Ruikar, M. (2013). National statistics of road traffic accidents in India. J Orthop Traumatol Rehabil (Serial Online), 6, 1-6. https://doi.org/10.4103/0975-7341.118718

Schmanski, D. W. (1987). U.S. Patent No. 4,715,743. Washington, DC: U.S. Patent and Trademark Office.

United Nations Road Safety Collaboration. Retrieved from http://www.who.int/roadsafety/en

World Health Organisation. Road Traffic Injuries Fact Sheet NO 358, March 2013. Retrieved December 25, 2018, from http://www.who.int/mediacentre/ factsheets/fs358/en/

\section{Copyrights}

Copyright for this article is retained by the author(s), with first publication rights granted to the journal.

This is an open-access article distributed under the terms and conditions of the Creative Commons Attribution license (http://creativecommons.org/licenses/by/4.0/). 